\title{
Mechanisms of meaning making in the co-occurrence of pragmatic markers with silent pauses
}

\author{
E R I K S C H L E E F \\ University of Salzburg, Austria
}

\section{A B S T R A C T}

This study explores the social meanings of unfilled pauses, you know, like, and combinations thereof by comparing the evaluation of speech with these features to speech without them. The comparison is based on a set of perception surveys in which participants listened to manipulated audio stimuli and rated them on a series of scales. Unfilled pauses are evaluated differently from all other features: they are rated high on Status and low on Dynamism. Where significant differences emerge, the pragmatic markers you know, like, and combinations of pauses with these are always rated lower than the guises without. They are most sensitive to personal characteristics in the Dynamism dimension, followed by Conversational Skills, Likeability, and Status. The mechanism that adapts the potential social meanings of linguistic features when they are combined hinges on the social salience of the features in question. Various outcomes are possible ranging from additive to non-additive effects. (Like, you know, attitudes, social meanings, prestige, solidarity, dynamism)

\section{N T R O D U C T I O N}

Recent research into the evaluation of individual standard and non-standard linguistic features, for example, -in vs. -ing (Campbell-Kibler 2007) and [?] vs. [t] (Schleef 2017), has found strong evidence of the context-dependency and dynamic nature of evaluation. The evaluation of linguistic features may depend on a variety of factors, including speaker and hearer characteristics (e.g. Hay, Warren, \& Drager 2006; Schleef \& Flynn 2015), region (e.g. Schleef, Flynn, \& Barras 2017), listeners' prior experiences and various contextual conditions, including eliciting conditions (Hay, Drager, \& Warren 2010) and topic (e.g. Campbell-Kibler 2009). This article explores one such contextual factor: that of the co-occurrence of linguistic features and how such co-occurrence may influence the evaluation of speakers.

Research in the third-wave variationist tradition has explored the indexical nature of linguistic and other features. It has shown that such features may be associated with a set of potential social attributes that are ideologically related (Eckert

(C) The Author(s), 2021. Published by Cambridge University Press. This is an Open Access article, distributed under the terms of the Creative Commons Attribution-NonCommercial-ShareAlike licence (https://creativecommons.org/licenses/by-nc-sa/4.0/), which permits non-commercial re-use, distribution, and reproduction in any medium, provided the same Creative Commons licence is included and the original work is properly cited. The written permission of Cambridge University 
2008) and that such social meanings are complex and dynamic. They are complex in that linguistic features may have a variety of often interconnected, potential social meanings, and they are dynamic as meanings may change from context to context. It follows that individual linguistic features occurring on their own may have different social meanings when they occur in combination with other features. The interaction of features with other linguistic and non-linguistic elements is key to indexicality theory: features can combine to form larger constructs or styles that have meaning to interlocutors. Such styles may index particular identities. For example, in her Belten High study, Eckert (2008:458) shows how the differential combination of vocalic and syntactic variables creates different styles and that each of these styles is associated with a different community of practice.

The majority of research in this tradition has focused on the production of such feature clusters into styles. More recently, research has explored how feature combinations are perceived. This is a crucial perspective to take. While research on style production has argued that features cluster into styles to create social meanings, it is by no means clear that listeners can actually perceive all features equally and recognize the intended meanings. This perception strand, thus, tests how different features combine into meaningful and socially legible constructs from the perspective of the hearer. The mechanisms that must be involved in processing the social meanings of co-occurring features remain rather obscure. The present article is an attempt to contribute to potential generalisations and to a theory of indexicality at this conceptual level, that is, regarding the perceived social meanings of individual versus co-occurring features. Thus, this study continues work of Levon (2007, 2014), Campbell-Kibler (2011), Pharao \& Maegaard (2017), and so on.

The very few studies that exist in the area of feature combination point to a complex picture: what precisely a linguistic feature may index depends on the features it co-occurs with and the social attributes that these other features index. Various outcomes of feature combinations are possible.

1. Some studies found social meanings of different features to be additive (Levon 2007; Campbell-Kibler 2011), so that (a) resulting meanings get strengthened or new meanings may emerge. For example, Levon (2007:545) shows that manipulations in pitch range and sibilant duration of 'gay'-derived stimuli have the most pronounced effect on listener ratings on the effeminate-masculine scale when pitch range and sibilant durations work together. Yet, the converse may, in principle, also occur: (b) If social meanings of two features are not compatible, the resulting meanings may get weakened.

2. Compatible social meanings of co-occurring features do not change at all.

3. Hearers may pay attention to only one feature and miss the social meanings of the other one (Levon 2014:557; Pharao \& Maegaard 2017:1163).

For example, Levon (2014) investigated mean pitch, ( characteristics of $/ \mathrm{s} /$, which are relevant in indexing gender, social class, and sexuality respectively among men in the UK. He concludes that in addition to social factors, the activation of social meanings is influenced by cognitive constraints, 
which, in certain contexts, result in listeners attending selectively to certain features in the speech stream when evaluating speech. For example, while elevated mean pitch results in lower competence ratings, this effect was neutralized when sibilance was added to the speech stream. This is a non-additive effect that, he argues, is due to selective non-attention. Similarly, Pharao \& Maegaard (2017) investigated unfronted and fronted $/ \mathrm{s} /$ and fronted and palatized $/ \mathrm{t} /$ in two registers of Copenhagen speech: 'modern Copenhagen speech' and 'street language'. Fronted /s/ indexes femininity and gayness in modern Copenhagen but not in the street register. When these variants are combined, results differ depending on how they are ordered: palatized $/ \mathrm{t} /$ makes males in the modern register appear less feminine, but only if listeners have not heard them produce a fronted $/ \mathrm{s} /$ before they produce the palatised /t/. Pharao \& Maegaard (2017:1161) argue that this effect is due to strength of association between variants and their potential social meanings. Fronted /s/ has a stronger link to gender and sexual orientation than those between palatized $/ \mathrm{t} /$ and attributes associated with 'a streetwise persona'.

Rather than also focusing on phonetic variation, this article explores the perception of three discourse features. I aim to find out what contribution, if any, unfilled pauses make when they co-occur with you know and like and what mechanisms are involved in generating new social meanings when two features co-occur. This is investigated by conducting a series of matched guise tests with manipulated guises which differ in the presence or absence of unfilled pauses, you know, like, and combinations thereof.

\section{A N A L Y T I C A L F R A M E W OR K S}

There are various ways in which the perception of linguistic features can be characterized: They may, of course, differ in the social attributes with which they are associated, but also in their degree of social salience. The term social salience is often used to refer to 'the relative availability of a form to evoke social meaning' (Levon \& Fox 2014:185). There are two related but initially independent frameworks in which perceptual work is often discussed. Much of this work is located in ideas from the field of person perception within social psychology (e.g. Levon 2014; Pharao \& Maegaard 2017). The focus here is on the role stereotypes play in linking group concepts (e.g. teenager) with social attributes (e.g. informal) and roles. This concept-attribute link may have different degrees of strength (e.g. Fazio 1986, 2007). The notion of attitude strength is based on the idea that situations in which listeners have encountered a specific form impact the relative attitude strength that listeners maintain towards this form. Here, attitudes are viewed as associative relationships between an object and a summary evaluation of the object as it is stored in a listener's memory (Fazio 2007; Bohner \& Dickel 2011). When we encounter a relevant object, for example, the discourse particle (DP) like, these summary evaluations become activated. Different types of attitudes are differentiated. There are attitudes that become activated automatically, whenever the object is 
encountered, and there are other attitudes that are not processed in an automatic, but rather a more deliberate fashion (Fazio 2007). Attitude strength refers precisely to this variability in attitude activation. The social distribution of a variable influences its attitude strength (Levon \& Fox 2014:200; Schleef 2017:50-52): variables with more pronounced social distributions are more likely to have higher levels of attitude strength.

A further analytical notion that may be relevant to explaining varying degrees of associations of features with social meanings, styles, and so on comes from linguistic anthropology, particularly the work of Agha (2005) and Silverstein (2003). It helps us explain how social meanings can come to be connected to the linguistic choices that interlocutors make. The notions of indexicality and enregisterment are crucial in this framework. Processes of enregisterment are those in which 'distinct forms of speech come to be socially recognised (or enregistered) as indexical of speaker attributes by a population of users' (Agha 2005:38). When a linguistic form becomes included in a register, it has been enregistered. For example, Johnstone, Andrus, \& Danielson (2006) describe the historical enregisterment process of monophthongised /aw/ in Pittsburgh as it shifted from not getting noticed to an association with social class and eventually a connection with Pittsburghese.

Although attitude strength is not part of this framework, different degrees of enregisterment relate to somewhat similar issues (see e.g. Johnstone et al. 2006). Enregistered features are likely to have high levels of attitude strength and social salience. The focus on the interconnectedness of different features and social meanings is an important advantage of the enregisterment model. In contrast, the research strand that is based on attitude strength can shed much light on the mechanisms that influence what happens to social meanings when two or more features combine. Aspects of social attribute compatibility, attitude strength, but also cognitive constraints that may result in selective non-attention all appear to influence this process and result in different outcomes.

To examine the effect of degree of social salience and how individual and combined features may differ in their evaluative dimensions, unfilled pauses and pragmatic markers represent an ideal test case. Unfilled pauses can combine with many pragmatic markers. They differ from some pragmatic markers, for example the discourse particle like, in that unfilled pauses are not subject to the same degree of social salience as like is (Schleef 2019). While this is also true for the pragmatic marker you know (Beeching 2016:151), the latter shares with the discourse particle a manner of evaluation that differs from that of unfilled pauses. Pauses are not typically discussed under the heading of informal or non-standard variable speech, and they appear to be associated with a set of particular social meanings (see next section). In contrast, the two pragmatic markers are associated with informal language and previous research would suggest that they differ in their social meanings and the degree to which they are associated with social meanings (Beeching 2016). While the social meanings of these three features are specified in more detail in the next section, for now, I can conclude that they seem to differ from each other as follows: 
Unfilled pauses:

Discourse particle like:

You know: low social salience, unmarked for formality

high social salience, informal

lower social salience than like, informal

These differences allow me to combine features with social meanings that are similar in some respects but different in others, determine how these conditions and social meanings influence perception, and track the evaluative outcome of feature combinations, regarding meaning strengthening, weakening, lack of change, and selective nonattention. This is important as previous research outlined above has begun to question the idea that combinations created by the speaker can actually all be 'read' by the hearer. Before I outline my methods in detail, I review what we know already about the two pragmatic markers and their co-occurrence with unfilled pauses.

PA A S E , PR A G A T I M A R E R S, A N D THEIR

E V A L U A T I O N

\section{Unfilled pauses, like, and you know}

Both the pragmatic markers you know and like are associated with pauses. Indeed, regarding like, different functions of like are associated with pausing behaviour in different ways. I follow D'Arcy's (2007) division of vernacular like functions into approximative adverb, discourse marker, discourse particle, and quotative be like. Approximative adverbs signal approximation, quotatives introduce reported speech, and discourse markers and particles mark information structure respectively outside and within clauses, as in (1), where instances of the particle have been underlined.

(1) Like we wouldn't really like go on a train to like Birmingham or something like that, it would just be like too far. (London 023, Thomas, 13)

It has been variously suggested (e.g. Siegel 2002:38; Fought 2006, quoted in D'Arcy 2007:413f) that it is one of the functions of like to act as a pause filler. Quoting Anderson (2000:19) and Levey (2003:28), D'Arcy qualifies that this may be the case for the particle in some contexts but cannot hold for the other functions of like as they do not frequently co-occur with self-repair and hesitation phenomena. Drager's (2011:705) work confirms the particle's association with pauses. She found the discourse particle like more often to be preceded or followed by a pause than grammatical and quotative like, which makes the particle a good candidate for an investigation of variable co-occurrence of like with pauses. Still, pauses are not obligatory in this function of like. This is in contrast to mirative like, another, yet less frequent, function of like that has to be followed by a longer pause to mark following information as surprising (Beltrama \& Hanink 2018:9). Degree and length of pauses associated with the discourse particle are variable (Schleef \& Turton 2018:54). 
The pragmatic marker you know is quite flexible and can occur in initial, medial, and final position (Crystal \& Davy 1975:92-95). Regarding you know's co-occurrence with pauses, Holmes' (1986:8-11) detailed description of the different functions of you know is most helpful. She differentiates between those functions of you know that express certainty and those that express uncertainty. You know functions in the former category to indicate certainty on the side of the speaker that the addressee has sufficient background knowledge, experience, and attitudes to understand what is being said. It expresses conjoint knowledge or confidence that the addressee knows what the speaker is talking about. The certainty category also includes instances where you know is used to emphasise and reassure the addressee that the proposition made is a valid one (Holmes 1986:7), as in example (2) (/ indicates a pause).

(2) I'm the boss around here you know // (Holmes 1986:8)

You know can also function as an expression of message-oriented or addressee-oriented uncertainty (Holmes 1986:7). This includes cases where you know signals an 'appeal for reassurance', as in example (3) (Holmes 1986:10, spelling adapted).

(3) and it was quite // well (lengthened) it was all very embarrassing you know

The uncertainty category also includes cases of you know signalling 'uncertainty concerning aspects of the linguistic expression of the proposition' (Holmes 1986:10). You know asks the listener for some tolerance as the speaker is engaged in searching for the appropriate way to continue an utterance. This may concern lexical imprecision when the uncertainty involves a phrase or a word, as in example (4).

(4) The money seems to be going for basics rather than for things like / you know extra equipment.

This category may also include cases where the speaker signals information that they wish to qualify, by either clarifying it or making it more precise, and cases where the speaker may use you know to signal a 'change of syntactic direction' by indicating a false start (Holmes 1986:11).

Holmes confirms that while for all of these functions pauses are variable, at the same time, there are some tendencies regarding syntactic position and pause distribution.

- The functions of expressing conjoint knowledge, appealing, and emphasis are sometimes followed by a pause.

- The function of indicating false starts is often preceded or followed by a pause.

- When introducing qualifying information, you know may be preceded by a brief pause.

- When signalling lexical imprecision, you know occurs clause-internally and is often preceded by a 'mid-length' (Holmes 1986:5) unfilled or filled pause. 
Thus, the most suitable you know function for a comparison with the discourse particle like is the function of you know that signals lexical imprecision. It is a match in terms of syntactic position and pause distribution, as both the discourse particle like and lexical imprecision you know can be preceded by a pause.

\section{Evaluation of pauses}

Within variationist sociolinguistics, pauses have received comparatively little attention. Kendall's (2013) macro-linguistic study is a notable exception. He links social characteristics of speakers to their pause production and finds that males and speakers from the Southern US have longer pauses than females and speakers from other US regions (2013:117-19). Tannen (1985:109) reached similar findings of regional-cultural differences in her study of Californians and New York Jewish speakers, the former of which prefer somewhat longer pauses than the latter. These studies support the view that pauses have a social component, and that their use should result in some degree of evaluation. Pauses can be viewed as important components of conversational styles (e.g. see Tannen 1985), which is a view that accords with current, third-wave approaches to language variation. Psycholinguistic research has also provided us with insights into context and length of pauses. For example, pauses are shorter and less likely before predictable words, function words (Warren 2013:40), and speech tasks requiring less planning (Goldman-Eisler 1968:51-56).

In order to find out whether pauses are subject to evaluation that could be documented in the matched-guise framework, I conducted a pilot study on the evaluation of unfilled pauses comparing them with speech without such pauses (Schleef 2019). Results have shown that pauses seem to be entangled in a complex web of indexical meaning: they are evaluated on a Prestige and a Dynamism dimension, but not at all on the Solidarity dimension. Guises with pauses are rated as more articulate, educated, and so on, but they are equally rated as less assertive, confident, and so on than guises without pauses. To an extent, this is in line with Walker's (1985) non-experimental study of the effects of witnesses' pause patterns on the impressions lawyers formed of them in pretrial legal proceedings. Unfilled, silent pauses in answers to the lawyer made witnesses appear nervous, afraid, recalcitrant, not spontaneous, and not careful in their answers (Walker 1985:69). Any positive effect that unfilled pauses may have had were not documented in Walker's study.

\section{Evaluation of you know and like}

Both like and you know are also subject to noticeable evaluation and stereotyping. You know and approximative like have been considered in Beeching's (2016) study of pragmatic markers in British English. She conducted a short text-based attitude study for these, probing their evaluation on four scales: politeness, directness, educatedness, and friendliness. Beeching (2016:114-15) found you know in 
utterance-final position to be perceived as somewhat more indirect and - especially among older speakers - less educated than the utterance without you know. Politeness and friendliness were not affected. Overall, Beeching concludes that utterancefinal you know has the capacity to index an informal and relaxed persona and that it is not particularly salient, nor sociolinguistically stigmatised.

Similar to you know, approximative like seems to make an utterance appear uneducated and indirect (even more so than you know), without affecting politeness and friendliness ratings overall (Beeching 2016:151). Speakers using the discourse particle like are heard as more attractive, cheerful, friendly, and successful but, simultaneously, they are perceived as less educated (Dailey-O'Cain 2000:75). Evaluations do seem to depend on the social characteristics of the listeners, particularly their age. Both Beeching (2016) for the approximative and Buchstaller (2014:208) for the quotative have shown that, in contrast to older people, many younger people exhibit neutral or positive attitudes toward the vernacular variants of like (Buchstaller 2014:208). Apart from demographic factors, personality traits, too, may mediate the evaluation of pragmatic markers (Hesson \& Shellgren 2015).

Maddeaux \& Dinkin (2017) is one of a few studies that compares the evaluation of different like functions. Using nine guises each of which contained ten tokens of a single like function, they compared a text without like to texts with like functioning as verb, preposition, comparative, quotative, discourse marker, pre-verbal discourse particle, discourse particle preceding a noun, and approximative adverb. Maddeaux \& Dinkin (2017) found that not all like functions embody the same meanings. Only one of the vernacular functions differs significantly from the neutral guise when heard by participants, most of which were undergraduates at the University of Toronto: the discourse particle like preceding a noun is heard as significantly less articulate, confident, and intelligent. This is interesting because significant evaluations have been documented for quotatives in written stimuli (e.g. Buchstaller 2014; Davydova, Tytus, \& Schleef 2017). These contrasting findings may be due to elicitation methods, region, or context of occurrence.

\section{Interim summary}

I have shown in this section that both like and you know may variably co-occur with pauses and that, in terms of pause distribution and syntactic structure, the discourse particle like and you know in its function of indexing lexical imprecision are the best candidates for a study that compares like, you know, and unfilled pauses by themselves, and combinations of unfilled pauses with you know or like. I should point out at this juncture that these three features are not variants of the same variable. Although some of their functions are overlapping, they can of course differ, but scales included in the perception test, to which I now turn, should capture at least some of these different functions. 
It has also become clear that all three features are subject to evaluation and that this evaluation may be mediated by demographic factors and the context of occurrence. Overall, there appears to be a trend for pauses to be heard as statusful but less dynamic than guises without pauses, while the occurrence of like and you know may increase a person's social attractiveness whilst reducing their status. However, the degree to which this may happen seems to differ: like appears to be more socially salient than you know, which would suggest that there is a more pronounced strength of association between the DP like and its potential social meanings than there is for you know; or to view this situation from a different perspective-as one of the reviewers suggested - the enregisterment of the discourse particle like may be more entrenched than that of you know.

\section{E T H O D S}

\section{Preparing the experiment: The guises}

An experimental online perception study was set up in which study participants listened to matched guises and evaluated them in an online survey. In order to prepare the guises, three short interview sections of roughly seventy words each were extracted from the British National Corpus. Each of these contained the pragmatic marker you know. They each report the actions of others, but the subject matter as such is different. The excerpts were modified somewhat to make them suitable for the inclusion of unfilled pauses and the discourse particle like.

I prepared different versions of these three texts: three versions without pragmatic markers and noticeable pauses, three versions with you know, three versions with like, and three versions with short unfilled pauses inserted as well as three versions each of combinations of unfilled pauses and you know and unfilled pauses and like with pauses inserted BEFORE these pragmatic markers (three tokens each). The different versions of these excerpts were each re-enacted by two mid-twenties females from Greater Manchester: Bella, who spoke with a middle-class Northern accent and a mean pitch of $199 \mathrm{~Hz}$, and Dana, who spoke with a local Manchester accent and a mean pitch of $197 \mathrm{~Hz}$. Considering the number of guises that were required for each of these speakers, I limited this study to only two speakers.

Recordings were conducted in a recording studio at the University of Manchester. Speakers wore head-mounted microphones. Audio data were recorded using a Zoom $\mathrm{H} 4$ recorder at a sampling rate of $44.1 \mathrm{kHz}$. In order to ensure that extracts do indeed only differ in the (non)occurrence of a pause or pragmatic marker, the guises without pragmatic markers and relevant pauses were used as stimuli matrices and each three (combinations of) pauses and pragmatic markers were inserted into these in Praat (Boersma \& Weenik 2014); see Table 1. I refer to the guises without pragmatic markers and relevant pauses as 'neutral', which alludes exclusively to the absence of pragmatic markers and relevant pauses, not to any other kind of 'neutrality'. 
TABLE 1. Overview of guises.

\begin{tabular}{|c|c|c|c|c|c|c|c|}
\hline & Topic & Neutral & Pause & You know & Pause + you know & DP like & Pause + like DP \\
\hline \multirow[t]{3}{*}{ Dana } & Tough Company & 1 & 1 & 1 & 1 & 1 & 1 \\
\hline & Sick Sam & 1 & 1 & 1 & 1 & 1 & 1 \\
\hline & Upset Alex & 1 & 1 & 1 & 1 & 1 & 1 \\
\hline \multirow[t]{3}{*}{ Bella } & Tough Company & 1 & 1 & 1 & 1 & 1 & 1 \\
\hline & Sick Sam & 1 & 1 & 1 & 1 & 1 & 1 \\
\hline & Upset Alex & 1 & 1 & 1 & 1 & 1 & 1 \\
\hline
\end{tabular}

This resulted in six versions each of the three excerpts per speaker, a total of thirty-six guises, each version of which differs only in the (non)occurrence of three pauses, pragmatic markers, or combinations of pragmatic markers and pauses. Since each pragmatic marker and pause was originally embedded in a sentence that was identical to the one into which they were spliced, these splicings fit neatly into the intonation contours of the new sentence frame.

Pooling results on the potential occurrence of you know, like, and pauses (Maclay \& Osgood 1959; Holmes 1986; D'Arcy 2007; Kahng 2018), pauses and pragmatic markers were inserted within clauses and before adjective phrases, noun phrases, and a prepositional phrase in one case. In complex verb structures, pauses and pragmatic markers were inserted after the first auxiliary as Maclay \& Osgood (1959:31) document a somewhat lower likelihood of pauses occurring before the first auxiliary. The neutral excerpts included no other pragmatic markers and no other within-clause silences above $100 \mathrm{~ms}$. When inserting unfilled pauses into the guises, only the pauses as such were inserted (see Duez 1993 for the ability of lengthened vowels to cue a pause).

Pauses had to be long enough to be noticed. Speakers vary when it comes to hearing a pause. The generally accepted standard auditory threshold seems to lie at about 200 to $250 \mathrm{~ms}$ (Zellner 1994:44). I was aiming to select a duration at the lower end of pausing, one that is equal or above $250 \mathrm{~ms}$. After experimenting with 200 and $250 \mathrm{~ms}$ pause duration in Manchester focus groups, it emerged that these were slightly too short in excerpts of the speech rate I was aiming to use to be noticed by all speakers. For this reason, $300 \mathrm{~ms}$ were selected for the experimental guises.

A further design decision concerned the number of tokens to insert into each guise. Due to the high number of guises that were investigated in this study, token number could not be varied and had to remain stable. Bortfeld, Leon, Bloom, Schober, \& Brennan's (2001:134) measures of disfluency rates in conversations recorded at Stanford University provided some guidance as to how many pragmatic markers and pauses to insert into the guises without them sounding unnatural. They provide total rates of disfluencies for various social groups and found these to range between 5.24 and 7.36 per 100 words. Since these included various different types of repeats and restarts, I considered five pause or pragmatic marker 
insertions in 100 words to be my upper limit for this study. The text stimuli I used had a mean word frequency of seventy-six, so three tokens were inserted into each stimulus.

To avoid exponential increases in the number of guises, several factors that may potentially influence the evaluation of guises remained stable. These include: pause length, position of pauses and pragmatic markers, the task, the place of residence of participants, and the sex of the speakers. Once all guises had been prepared, selected stimuli were played to small focus groups of undergraduate students, and impressions of the excerpts were invited based on a structured set of questions. This was done in order to collect relevant terms used by listeners to express their evaluations and to test stimuli reliability. Participants in these focus groups appeared to remain unaware of the manipulated nature of the stimuli.

\section{Preparing the experiment: The survey}

Since it was impossible for every participant in the study to listen to and evaluate all thirty-six guises, twelve online surveys, each containing three guises (see Table 2), were generated in SurveyGizmo (2015). The thirty-six guises were distributed across these twelve surveys in such a way that (i) topics and guise types were never repeated, (ii) each participant heard both Bella and Dana at least once, and (iii) the order of guises within each survey was randomized each time a new participant entered a new survey, in order to counteract order effects in the results. Thus, every participant heard only one guise of a topic set per speaker. This betweensubjects design is particularly suited for experimental setups like this study where the same speaker hears three guises and for each repeats the experiment. The between-subjects design also reduces survey time and, crucially, circumvents the problem of the listener recognizing the speaker. In contrast, a within-subjects design would create undesirable practice and demand effects, sensitization, and carry over (Greenwald 1976:314) under such circumstances.

Each of these twelve subsurveys contained a welcome page with an audio test and a short training set, which took less than a minute to work through. The very end of each survey included questions about the respondents, their self-reported sex, age, social class, and so on. The three pages in between the welcome page and final page were dedicated to one guise each. Each of the three pages consisted of a total of eight questions that were made up of a set of social attributes, which I refer to as scales. A total of twenty-nine scales were included (see the appendix; the survey is available upon request).

Scales were randomized in each individual survey based on a procedure within SurveyGizmo in order to prevent item order affecting the results. Every participant would be asked to listen to the guise presented on a page and rate it using the scales distributed across eight questions. These scales were provided in the form of sevenpoint semantic differential scales or sliders. Informants were asked to indicate the degree to which these words applied to the voice they heard. 
TABLE 2. Guise distribution across twelve subsurveys.

\begin{tabular}{|c|c|c|c|c|c|c|c|c|c|c|c|}
\hline S 1 & S 2 & S 3 & S 4 & S 5 & S 6 & S 7 & S 8 & S 9 & S 10 & S 11 & S 12 \\
\hline Bella Neutral & $\begin{array}{l}\text { Bella pause }+ \\
\quad y k\end{array}$ & $\begin{array}{l}\text { Bella } \\
\text { pause }\end{array}$ & Bella $y k$ & $\begin{array}{l}\text { Bella pause }+ \\
\quad \text { like }\end{array}$ & Bella like & Dana neutral & $\begin{array}{l}\text { Dana pause }+ \\
y k\end{array}$ & $\begin{array}{l}\text { Dana } \\
\text { pause }\end{array}$ & Dana $y k$ & $\begin{array}{l}\text { Dana pause }+ \\
\quad \text { like }\end{array}$ & Dana like \\
\hline $\begin{array}{l}\text { Dana pause }+ \\
y k\end{array}$ & Dana neutral & Dana $y k$ & Dana pause & Dana like & $\begin{array}{l}\text { Dana pause + } \\
\text { like }\end{array}$ & $\begin{array}{l}\text { Bella pause }+ \\
\quad \text { like }\end{array}$ & Bella like & Bella $y k$ & Bella pause & Bella Neutral & $\begin{array}{l}\text { Bella pause }+ \\
\quad y k\end{array}$ \\
\hline Bella yk & $\begin{array}{l}\text { Bella pause }+ \\
\quad \text { like }\end{array}$ & Bella like & $\begin{array}{l}\text { Bella } \\
\text { neutral }\end{array}$ & $\begin{array}{l}\text { Bella pause }+ \\
\quad y k\end{array}$ & Bella pause & Dana $y k$ & $\begin{array}{l}\text { Dana pause }+ \\
\quad \text { like }\end{array}$ & Dana like & $\begin{array}{l}\text { Dana } \\
\text { neutral }\end{array}$ & $\begin{array}{l}\text { Dana pause }+ \\
y k\end{array}$ & Dana pause \\
\hline
\end{tabular}


Long surveys tend to reduce response rate and data accuracy, so I prioritised those scales that were mentioned during focus groups, as they were more likely to be relevant to the features of interest. I also made sure to include scales that I expected to be relevant to the evaluation of pauses and pragmatic markers (e.g. regarding clarity and fluency, gender and politeness) but also those traditionally used in studies that investigate the evaluation of non-standard varieties and features, regarding Prestige, Solidarity, and Dynamism (e.g. Zahn \& Hopper 1985).

To balance uptake, a procedure within SurveyGizmo was used to randomise access to one of the twelve surveys. Every participant started the survey on the welcome page but was then randomly assigned to one of the twelve subsurveys as they moved on to the next page. Participants in the experiment were required to have lived in Greater Manchester for at least ten years, so the survey consists of people from Greater Manchester hearing Manchester stimuli. In order to recruit study participants, flyers and emails were sent to schools and universities for distribution to pupils and students. The survey was also advertised on a social networking site. Once a respondent completed the survey, they were sent a thank you email asking them to pass on the survey to their family and friends. Respondents were reimbursed for their efforts with a five-pound gift certificate.

\section{Data analysis}

A total of 1,094 respondents accessed the survey. Responses from 455 participants were removed from the data set because they did not finish the survey $(\mathrm{N}=324)$ or did not meet the target criteria $(\mathrm{N}=131)$ : they had non-UK IP addresses, did not live in the target area, claimed not to speak English natively, or rushed through the survey. It took a minimum of five minutes and thirty seconds to take the survey. This is based on a test phase with a small group of people who took the survey in the presence of the researchers and then answered questions about their experience. Surveys with response times of less than that were disregarded. This left a total of 1,917 responses from 639 respondents.

The majority of respondents were between twenty and forty-five years old. 301 respondents were male and 338 were female. Class background was based on selfreported evaluation on a slider, which participants could move on a scale that ranged from a label that read working class on the left to one that read upper class on the right, with middle class inserted at midpoint. 146 respondents placed themselves in the first $30 \%$ of the scale, that is, on the working-class side, forty-five in the last $30 \%$ of the scale on the upper-class side, and all remaining responses placed themselves on various points of the scale between these two.

Respondent ratings were subjected to statistical testing using $\mathrm{R}$ ( $\mathrm{R}$ Core Team 2019). Data from matched guise studies are usually first subjected to a factor analysis, a technique that uncovers whether response patterns on a number of scales can be explained by a smaller number of underlying factors (Streiner 1994:135). Evaluations for each group of scales (= factors) were then subjected to statistical testing 
using mixed-effects linear regression in $\mathrm{R}$ for the rating responses. Respondent was entered as random effect. Models with random slopes did not improve the model fit (based on AIC and BIC measures), so adding complexity to the models was not considered worthwhile. The ratings for the factors were treated as the response variable with the following fixed-effect predictors:

- Feature present in the stimulus: neutral (no pause, no pragmatic markers), pauses, you know, pause + you know, like, pause + like

- Topic: Tough Company, Sick Sam, Upset Alex

- Speaker: Bella, Dana

- Respondent sex: male, female

- Respondent class: continuous

- Respondent age: continuous

I also checked for interactions between the linguistic feature present and the other variables. A step-down method was used to construct the most efficient model, with ANOVAs testing the improvement of successive models. In this study, the risk of cumulative error is somewhat increased since many of the scales access similar evaluative domains. In addition, multiple comparisons with different topic reference levels were conducted. I used the Bonferroni correction (Baayen 2008:106) to address the risk of cumulative error by dividing the alpha value of 0.05 by the number of comparisons, two, which results in a significance level of 0.025 , below which predictors were considered significant and included in the statistical model.

\section{R E S U L T S}

First, a factor analysis was conducted. A parallel analysis, using a function available in the psych library of the statistics programme R, reveals that five factors are sufficient to describe the data. The number of factors was then entered in the instructions to run a promax rotation on the ratings of the personality traits using the principal axis factoring (PAF) method with Kaiser Normalisation (Costello \& Osborne 2005:2).

The factor analysis yielded an output that indicates how strongly scales load on the five factors. I considered a scale to be loading on a factor if it had a primary loading of at least .5 and no secondary loading above .3. If more than two scales in a factor met these criteria, they were conflated to a single factor in any further statistical investigation.

Four factors met these criteria, and they were named Status, Likeability, Dynamism, and Conversational Skills. The first three factor groups resemble those of many other studies. The Status group indicates the degree to which a speaker was viewed in relation to social characteristics that relate to social status. It includes the scales articulate, attractive, class, educated, feminine, formal, intelligent, and posh. The occurrence of feminine here makes sense considering both speakers 
were female. The Likeability group indicates the degree to which a speaker was viewed as a likeable or good person. It includes the following scales: friendly, genuine, hardworking, reliable, and trustworthy. The Dynamism factor includes items that relate to speakers' social power, their activity level, but also selfrepresentational aspects of speech (Zahn \& Hopper 1985:119). It includes the assertive, authoritative, certain, confident, and fluent scales. The Conversational Skills factor is made up of the involving, experienced, and precise scales. The following scales did not meet the criteria to be conflated with any of the four scales and, due to space constraints, they will not form the focus of this article: clear, laidback, polite, outgoing, professional, perceived age, supportive, and trendy. Results of the factor analysis give us an idea of how the data is structured. To uncover the extent to which this structure overlaps significantly with the features under investigation, the four conflated scales were subjected to mixed-effects linear regressions. These models consider simple as well as interaction effects (see Data analysis section).

Tables 3 to 6 present the results for the Status, Likeability, Dynamism, and Conversational Skills scales, providing the factor level, estimate, and $p$-values. The second and fifth columns in Table 3 reveal how respondents rated the speaker guises on the Status scale. The results indicate that the feature (whether respondents heard a pause, like, you know, or a combination thereof) is significant for the simple pause guise as well as the pause + like guise. The estimate given for pause and pause + like DP helps us interpret the effect that the presence of one feature rather than another has on the rating given by respondents. Crudely, a positive value indicates that a higher rating than the reference predictor (no pauses, no pragmatic markers) is associated with the factor, while a negative value indicates that a lower rating than the reference predictor is associated with the factor. The estimate can be used as a measure of effect size across different factor levels that are compared to the same reference level. In Table 3, pause + like DP is associated with a lower value than the reference level. This indicates that it is rated as less intelligent, less attractive, less educated, and so on than the neutral guises without pauses and pragmatic markers. Conversely, the guises with pauses are heard as more statusful than the neutral guises. Thus, guises with only pauses and guises with a combination of pause and like have contrasting social meanings. Other social factors, such as the topic and speaker, were not significant in interaction with any of the features. Thus, the evaluation for Status holds across all speakers and topics investigated. Figure 1 summarises these results in the form of a boxplot (it reflects the seven-point semantic differential scales ranging from one to seven).

There are significant effects for topic and speaker in the model for the Status factor group (Table 3). However, there are no interaction effects between feature and topic or speaker. Thus, regardless of what feature respondents heard, the Tough Company topic is always rated higher than the Sick Sam topic and Dana guises lower than Bella guises. It is possible for the evaluation of a topic or speaker to influence how the different structures are evaluated, that is topic/speaker and feature may interact. This is not the case in the model presented in Table 3. 
TABLE 3. Best mixed-effects model for Status factor group $(N=1,917)$. Reference levels are Neutral guise, Bella, and the Sick Sam topic.

\begin{tabular}{lrcrr}
\hline \hline & Estimate & Std. error & $t$-value & $p$-value \\
\hline Intercept & 4.66 & 0.06 & 71.12 & $<0.01$ \\
Speaker (Dana) & -1.50 & 0.04 & -35.81 & $<0.01$ \\
Pause + like DP & $-\mathbf{0 . 1 7}$ & $\mathbf{0 . 0 7}$ & $-\mathbf{2 . 3 4}$ & $<\mathbf{0 . 0 2}$ \\
Like DP & -0.12 & 0.07 & -1.50 & 0.13 \\
Pause & $\mathbf{0 . 2 0}$ & $\mathbf{0 . 0 7}$ & $\mathbf{2 . 6 0}$ & $<\mathbf{0 . 0 1}$ \\
You know & -0.08 & 0.07 & -1.04 & 0.29 \\
Pause + you know & -0.01 & 0.07 & -0.18 & 0.85 \\
Topic (Tough Company) & 0.11 & 0.05 & 2.28 & 0.02 \\
Topic (Upset Alex) & -0.16 & 0.05 & -3.12 & $<0.01$ \\
\hline \hline
\end{tabular}

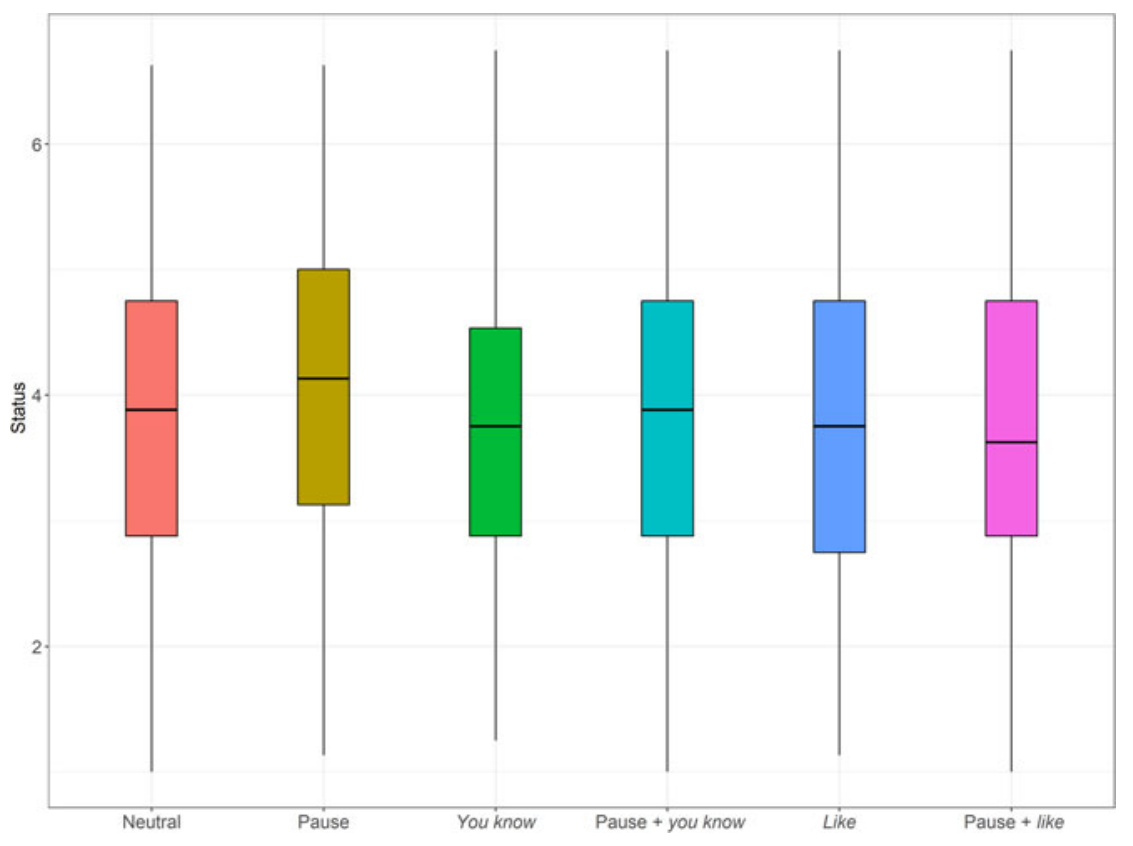

FIGURE 1. Status scales.

Results for the Likeability factor are strikingly different (see Table 4, Figure 2) from those of the Status factor: there is no statistically significant difference between guises with and without pauses. In addition, Likeability results for the pragmatic markers are significantly more negative than those of the neutral guise: guises with like and guises with a combination of like and a pause make speakers 
TABLE 4. Best mixed-effects model for Likeability factor group $(N=1,917)$. Reference levels are Neutral guise, Bella, and the Sick Sam topic.

\begin{tabular}{lrcrr}
\hline \hline & Estimate & Std. error & $t$-value & $p$-value \\
\hline Intercept & 4.58 & 0.06 & 66.82 & $<0.01$ \\
Speaker (Dana) & -0.16 & 0.04 & -3.57 & $<0.01$ \\
Pause + like DP & $\mathbf{- 0 . 2 9}$ & $\mathbf{0 . 0 7}$ & $-\mathbf{3 . 7 4}$ & $<\mathbf{0 . 0 1}$ \\
Like DP & $-\mathbf{0 . 1 9}$ & $\mathbf{0 . 0 8}$ & $-\mathbf{2 . 4 0}$ & $<\mathbf{0 . 0 2}$ \\
Pause & 0.04 & 0.07 & 0.51 & 0.61 \\
You know & -0.06 & 0.07 & -0.86 & 0.38 \\
Pause + you know & -0.13 & 0.07 & -1.67 & 0.09 \\
Topic (Tough Company) & 0.28 & 0.05 & 5.26 & $<0.01$ \\
Topic (Upset Alex) & -0.28 & 0.05 & -5.30 & $<0.01$ \\
\hline \hline
\end{tabular}

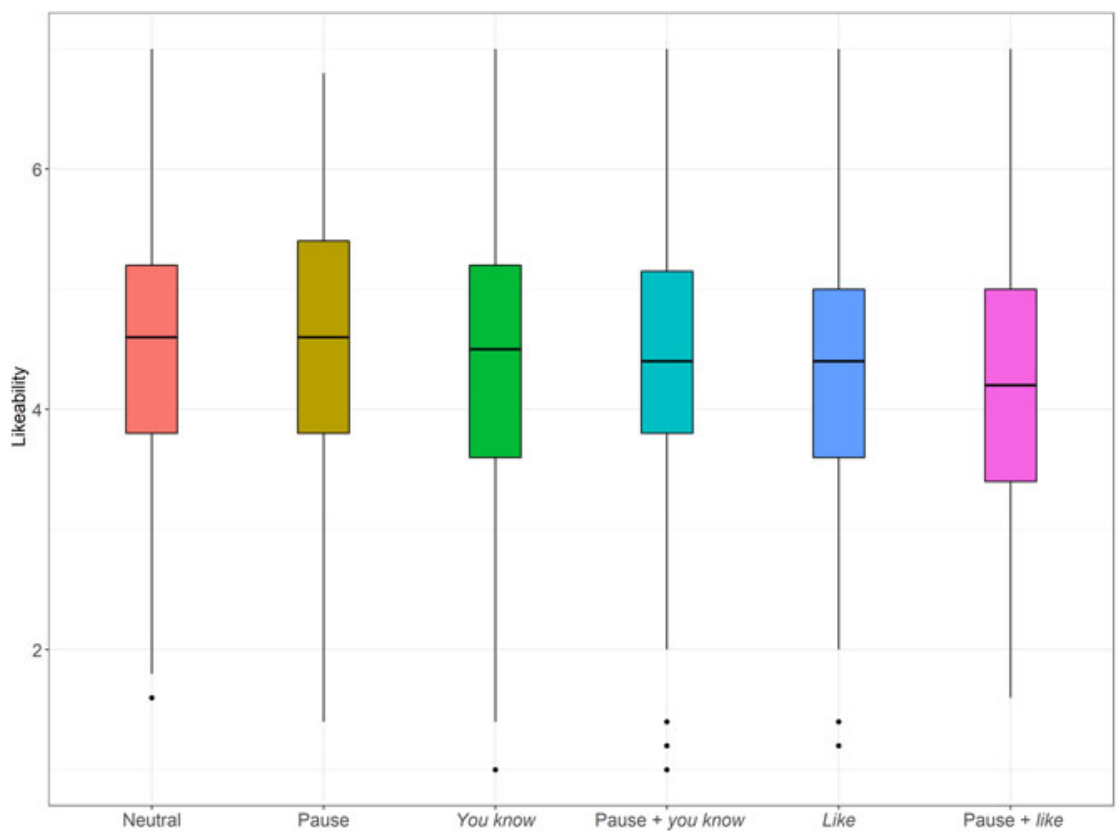

FIGURE 2. Likeability scales.

appear less genuine, less trustworthy, less friendly, less reliable, and less hardworking. It is also worth noting that the effect size for pause + like combinations, as indicated by the estimate, are stronger than those of simple like guises. For both the Status and the Likeability dimensions no statistically significant results emerge for any of the you know guises when compared to the neutral guise, which suggests that they are evaluated as equally statusful and likeable as the neutral guises. 


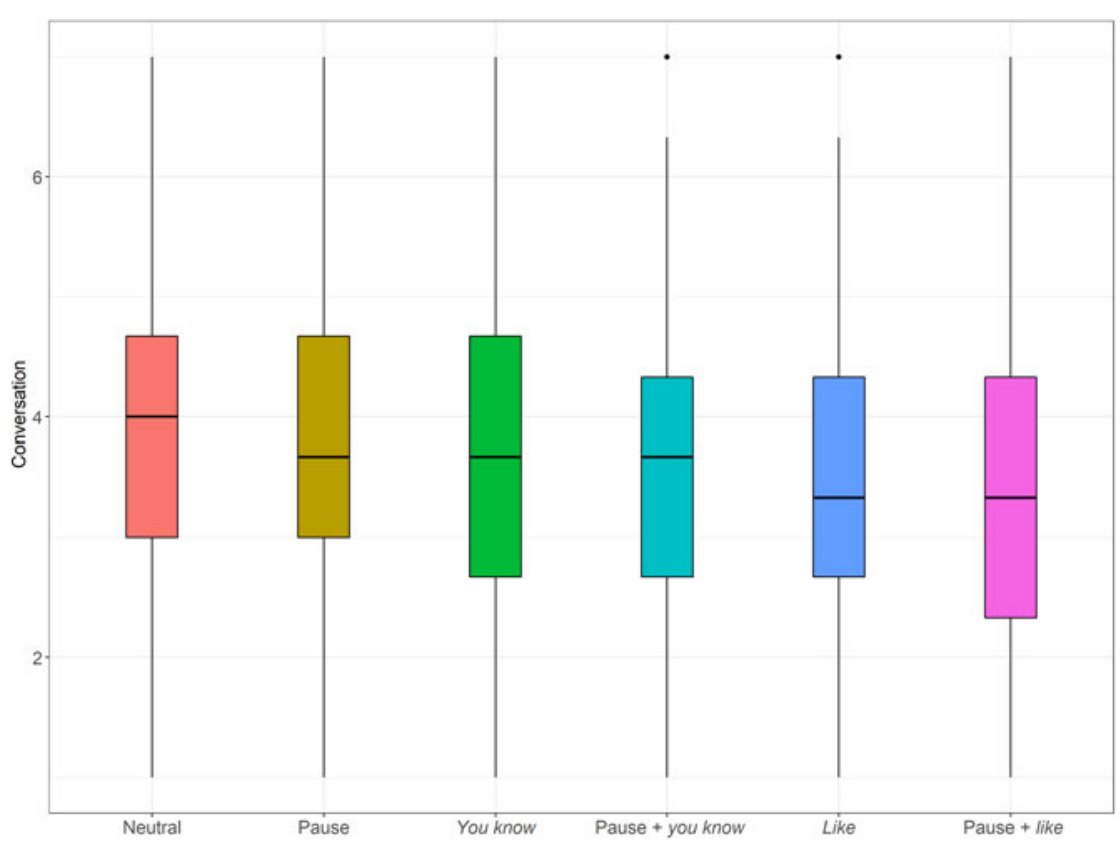

FIGURE 3. Conversational Skills scales.

Results for the Conversational Skills and Dynamism dimensions contrast with those of the Status dimension but continue the trend observed for the Likeability dimension. Conversational Skills of like, pause + like, and pause + you know users are rated as lower than the neutral guises (see Table 5, Figure 3). This is the only model in which an interaction between one of the features and the social characteristics of respondents emerges. There is a significant interaction effect between gender and the pause + like guises: while males follow the main trend of reducing the evaluation of Conversational Skills in the pause + like guises compared to the neutral guises, this is the case for females to a lesser degree.

In the Dynamism dimension, all guises are rated as less dynamic than the neutral guises. Pauses, pragmatic markers, and combinations thereof make speakers appear less assertive, less authoritative, less certain, less fluent, and less confident (see Table 6, Figure 4). It is once again noticeable that the effect sizes of simple pauses and pragmatic markers are weaker than combinations of pauses and pragmatic markers: pauses appear to increase the negative evaluation.

Several trends become apparent from the summary of results in Table 7. First, simple pauses are evaluated differently from all other features as they are rated high on Status, low on Dynamism, and equal to the neutral guises on Likeability and Conversational Skills. All other structures either do not differ from the neutral guises or they are rated lower than the neutral guises. 
TABLE 5. Best mixed-effects model for Conversational Skills factor group $(N=1,917)$. Reference levels are Neutral guise, Bella, female, and the Sick Sam topic.

\begin{tabular}{lrcrr}
\hline \hline & Estimate & Std. error & $t$-value & $p$-value \\
\hline Intercept & 4.13 & 0.09 & 42.16 & $<0.01$ \\
Speaker (Dana) & -0.46 & 0.04 & -10.07 & $<0.01$ \\
Pause + like DP & $\mathbf{- 0 . 2 6}$ & $\mathbf{0 . 1 1}$ & $-\mathbf{2 . 4 2}$ & $<\mathbf{0 . 0 2}$ \\
Like DP & $-\mathbf{0 . 4 4}$ & $\mathbf{0 . 1 1}$ & $-\mathbf{3 . 7 3}$ & $<\mathbf{0 . 0 1}$ \\
Pause & -0.13 & 0.11 & -1.17 & 0.24 \\
You know & -0.17 & 0.11 & -1.59 & 0.11 \\
Pause + you know & $-\mathbf{0 . 2 7}$ & $\mathbf{0 . 1 1}$ & $-\mathbf{2 . 4 0}$ & $<\mathbf{0 . 0 2}$ \\
Topic (Tough Company) & -0.06 & 0.05 & -1.24 & 0.21 \\
Topic (Upset Alex) & -0.24 & 0.05 & -4.52 & $<0.01$ \\
Respondent sex & 0.16 & 0.13 & 1.26 & 0.20 \\
{$[\ldots]$} & & & & \\
Respondent sex*Pause + like & -0.42 & 0.16 & -2.62 & $<0.01$ \\
\hline \hline
\end{tabular}

TABLE 6. Best mixed-effects model for Dynamism factor group $(N=1,917)$. Reference levels are Neutral guise, Bella, and the Sick Sam topic.

\begin{tabular}{lrcrr}
\hline \hline & Estimate & Std. error & $t$-value & $p$-value \\
\hline Intercept & 5.02 & 0.07 & 68.24 & $<0.01$ \\
Speaker (Dana) & -0.42 & 0.04 & -8.95 & $<0.01$ \\
Pause + like DP & $-\mathbf{0 . 5 6}$ & $\mathbf{0 . 0 8}$ & $-\mathbf{6 . 8 0}$ & $<\mathbf{0 . 0 1}$ \\
Like DP & $-\mathbf{0 . 3 1}$ & $\mathbf{0 . 0 8}$ & $-\mathbf{3 . 6 1}$ & $<\mathbf{0 . 0 1}$ \\
Pause & $\mathbf{- 0 . 2 2}$ & $\mathbf{0 . 0 8}$ & $-\mathbf{2 . 6 9}$ & $<\mathbf{0 . 0 1}$ \\
You know & $\mathbf{- 0 . 2 8}$ & $\mathbf{0 . 0 8}$ & $\mathbf{- 3 . 4 8}$ & $<\mathbf{0 . 0 1}$ \\
Pause + you know & $-\mathbf{0 . 4 7}$ & $\mathbf{0 . 0 8}$ & $-\mathbf{5 . 7 2}$ & $<\mathbf{0 . 0 1}$ \\
Topic (Tough Company) & -0.25 & 0.05 & -4.49 & $<0.01$ \\
Topic (Upset Alex) & -0.03 & 0.05 & -0.54 & 0.58 \\
\hline \hline
\end{tabular}

Second, the pragmatic markers are most sensitive to scales in the Dynamism dimension, followed by Conversational Skills, Likeability, and Status. This is likely due to the scales included in these dimensions. While the Social Status and Likeability dimensions in particular include scales that are of a primarily social nature, the Dynamism and Conversational Skills scales also speak to functional interpretations of pragmatic markers and pauses as they bear directly on the speaker's assumed knowledge state regarding certainty and confidence, but also affiliative stances, such as involvement, and so on. The general functions of these pragmatic markers do not change when combined with pauses but the indexical meanings of these may shift slightly, for example, to express more or less involvement.

Third, while evaluations in the Dynamism group are similar for simple pauses, you know, and like - in that occurrences of either of these make speakers seem less dynamic - the estimates in Table 6 demonstrate that the intensity of this reduction in Dynamism differs: the effect is strongest for like $(-0.31)$ followed by you know 


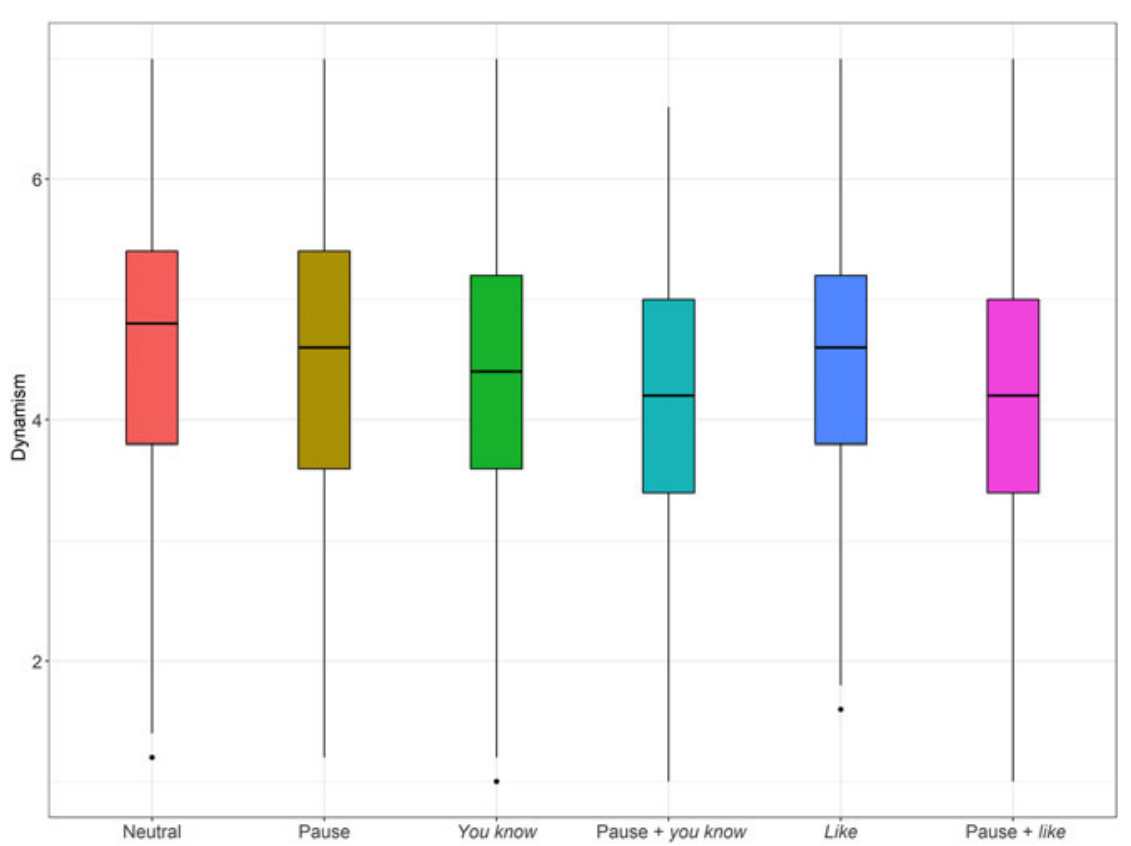

FIGURE 4. Dynamism scales.

$(-0.28)$, and unfilled pauses $(-0.22)$. At least for this scale, unfilled pauses and the pragmatic markers appear to differ in their attitude strength when compared to the neutral guise. Especially attitudes towards like appear to be processed in a more automatic fashion than those of you know and unfilled pauses.

Finally, Table 7 suggests that you know differs from the other structures in one additional aspect: the Dynamism scale appears to be the scale that is most relevant to this pragmatic marker. The social meanings of this you know function arise primarily out of its immediate pragmatic and processing contexts, which is most clearly reflected in the Dynamism dimension. This is in line with a new research strand that is located at the intersection of pragmatics and social perception, which has uncovered how social meanings of pragmatic structures are derived partly by their logical and/or pragmatic characteristics (Acton \& Potts 2014; Beltrama \& Staum Casasanto 2017). Results of the current study confirm this link.

\section{I S C U S S I O N}

It was the aim of this study to find out what contribution, if any, unfilled pauses make when they co-occur with you know and like and what mechanisms are involved in generating new social meanings when two features co-occur. Regarding 
TABLE 7. Overview of statistically significant results $(>$ more than neutral guise, $<$ less than neutral guise).

\begin{tabular}{lccccc}
\hline \hline Dimension & Pause & You know & Pause + you know & DP Like & Pause + like DP \\
\hline Status & $>$ & & & & $<$ \\
Likeability & & & & $<$ & $<$ \\
Conversational Skills & & & $<$ & $<$ & $<$ \\
Dynamism & $<$ & $<$ & $<$ & $<$ & $<$ \\
\hline \hline
\end{tabular}

the co-occurrence of linguistic features, I outlined several possibilities. Social meanings may:

1. be additive, so that resulting meanings (a) get strengthened, new meanings may emerge, or (b) the resulting social meanings may get weakened if meanings of two features are not compatible;

2. remain the same if social meanings of co-occurring features are compatible; or

3. may be limited to those of one of the features as the other feature is not attended to.

Two of these, 1 and 3, seem to play a role in meaning outcomes of combinations of unfilled pauses and pragmatic markers in various evaluative dimensions. In the discussion that follows I consider each of the four dimensions and assess them in respect to the mechanisms that may be involved in producing the social meaning outcomes.

\section{Dynamism: Additive effects}

When unfilled pauses are combined with the pragmatic markers, the effect of reduced dynamism that pauses $(-0.22)$, you know $(-0.28)$, and like $(-0.31)$ showed when compared to neutral guises is strengthened. This results in an effect size of -0.47 for pause + you know and -0.56 for pause + like. This appears to be a very straightforward example of additive meaning. The functional interpretations and social meanings of the three features overlap: combining them makes the resulting structures seem even less certain, less confident, less fluent, less assertive, and less authoritative than the neutral guises. If we accept that knowledge states of certainty and confidence can be gradient, adding up different markers of uncertainty appears to increase the degree of uncertainty. The Dynamism dimension tracks this effect.

Whether the effect is due to the social meanings of pauses or the increase in linguistic salience that pauses provide for the following pragmatic marker is an empirical question: the two phenomena are impossible to disentangle. One might argue at this point that an unfilled pause was an unfortunate choice for such a study due to the fact that social meaning and contextual salience cannot be differentiated; however, any other feature would have created the same conundrum. For example, a combination of you know + like might equally increase the salience of like, which could not be disentangled from the social meaning that you know brings into the equation. 
Conversational skills and likeability: Pauses increase linguistic salience

The second dimension that gives us a clue as to what indexical meanings the guises may have given rise to is the Conversational Skills dimension. It is made up of the involving, experienced, and precise scales. Guises with unfilled pauses do not significantly differ from the neutral guises, so they do not attribute any additional social meaning in this dimension by themselves. Nonetheless, combinations of unfilled pauses and pragmatic markers continue to have an effect-since social meaning is not relevant here, this must be due to the increase in linguistic salience that they afford to the pragmatic markers.

For both males and females, the occurrence of simple like results in a reduction of perceived Conversational Skills, but they react differently when like occurs with a pause: females increase ratings for Conversational skills slightly while still keeping them below those of neutral guises, but males reduce ratings drastically. This might suggest that the functional interpretations of like regarding involvement, experience, and precision are valued more by many women than many men, but only when the attention is drawn to like by means of a pause.

The you know guises also feature significantly in the Conversational Skills domain. The pause + you know guises are evaluated as more negative than the neutral guises. While the you know guises do not show a significant effect by themselves, the combination with pauses results in a significant difference between pause + you know and neutral guises. In respect to the three scenarios outlined at the beginning of the Discussion section, neither of these applies, as pauses do not have any significant social meanings to add - all they can do is increase the linguistic salience for the pragmatic markers and sharpen the interactional interpretations and social meanings. In this case an unfilled pause reduces the degree to which you know may express involvement, experience, and precision.

Results of the Likeability dimension (friendly, genuine, hardworking, reliable, and trustworthy) resemble those of the Conversational Skills dimensions. Guises with unfilled pauses do not significantly differ from the neutral guises, so they do not attribute any additional social meanings by themselves. Nonetheless, the increase in salience that pauses afford to the pragmatic markers appears to have an effect. While the guises with the discourse particle like are heard as less likeable than the neutral guises, the effect size of pause + like is stronger than that of the former, that is, pause + like guises are heard as even less likeable than like guises. The you know guises do not feature significantly in the Likeability dimension.

Status: Additive effect for pause + you know, selective non-attention for pause + like

Results for the Status domain (articulate, attractive, class, educated, feminine, formal, intelligent, and posh) are the most complex. Here pauses have social meaning to add in feature combinations, but this social meaning is very different 
from that of you know and like. The pause guises are heard as MORE statusful than neutral guises (see Schleef 2019). While you know guises do not appear to be significantly different from neutral guises in the Status dimension, pause + like guises are heard as less statusful than neutral guises (the effect size for the DP like by itself indicates a similar trend; see Table 3).

This allows us to explore what happens when two features are combined that differ in their social meanings. I first consider you know and then discuss like. There are no significant results for you know in this dimension. The effect size of -0.08 for you know guises without pauses suggests that they are rated similarly to neutral guises in the Status dimension. Adding pauses to you know tokens results in an even smaller effect size $(-0.01)$. There is no trace of the high status pause values documented for simple pauses $(0.20)$. This would suggest that pause insertions before you know weaken social meanings of both features, which is in line with scenario $1 \mathrm{~b}$ summarised in the Discussion section.

This is very much in contrast to the evaluation of like. The insertion of pauses before like results in pause + like guises to be evaluated as significantly different from the neutral guises. This negative assessment was not strong enough in guises of like without pauses to be statistically significant. Thus, the combination of the feature that has resulted in more statusful evaluation in the current experimental guises (pauses) with a pragmatic marker that is evaluated as slightly less statusful in these same guises (like) does not lead to weakening of the social meanings but a strengthening of the meanings of one of those features: like. This is in line with scenario 3. In his investigation of pitch, (TH)-fronting, and /s/, Levon (2014:557) argued very persuasively against a blocking of one linguistic feature by another. Instead, he advanced a proposal for selective non-attention: hearers pay attention to the feature that is more salient in a particular environment when social meanings differ. Based on his argumentation, he concludes that sibilance is the more salient feature when compared to (тн)-fronting. The current results for pause + like are in line with this view. Like cannot possibly have blocked the unfilled pauses because listeners clearly react to the increased linguistic salience that the unfilled pauses afford to like: it is now rated as less statusful than the neutral guises when like tokens without pauses were not significantly different from them. Listeners are likely attending to the higher social salience of like, its 'relative ability... to evoke social meaning' (Levon \& Fox 2014:185), while social meanings of unfilled pauses do not appear to be activated. That the social salience of like is high has also been argued elsewhere; (see e.g. Davydova (2021) on be like). The social salience of a feature is a function of its attitude strength as described above. Attitudes towards like appear to be stronger than those of unfilled pauses and you know in the Status dimension; they can be accessed in an automatic fashion, which results in this particular outcome for like but not you know.

Enregisterment (Agha 2005) is a further analytical notion that can be relevant to explaining the varying degrees of association of a feature with social meanings. I have mentioned previously that the enregisterment of like may be more 
entrenched than that of you know. Listeners are more certain about the social meanings of the discourse particle like and recognise its indexicalities more easily. The discourse particle is more strongly enregistered with an informal speech style and less academically minded individuals (less articulate, less educated, less intelligent, etc.). This is why the social meanings of like can trump those of pauses, while you know does not have the same effect. This is an important finding as it complicates the idea that speakers assemble features to create meaningful styles in an active manner. Results of this study suggest that not all social meanings of features that are combined by the speaker may be attended to by the listener.

\section{O N C L U S I O N}

In this study, I have attempted to establish potential generalisations and contribute to a theory of indexicality, in particular, regarding feature co-occurrence and resulting social meanings. Results support the idea that social meanings emerge out of constellations of different features and their potential social meanings. Outcomes $1 \mathrm{a}$ and $1 \mathrm{~b}$ are most clearly in line with such an interpretation. Outcome 2 would also have been a compatible outcome but was not documented here. However, outcome 3 presents a potential problem for indexicality theory, as not all features that are combined by the speaker may be attended to by the listener. This confirms findings by Levon (2014) and Pharao \& Maegaard (2017) suggesting that the mechanism that adapts the potential social meanings of linguistic features when they are combined, hinges not only on the compatibility but also the social salience of the features in question. This study has also confirmed that resulting social meanings of feature combinations are not simply interactions of social meanings but that other linguistic conditions contribute as well, specifically I have discussed the impossibility of separating the social meanings of unfilled pauses from the ability of pauses to increase the linguistic salience of following elements. This too is an aspect that indexicality theory should incorporate: social meanings of features alone are not sufficient to predict the meaning outcome.

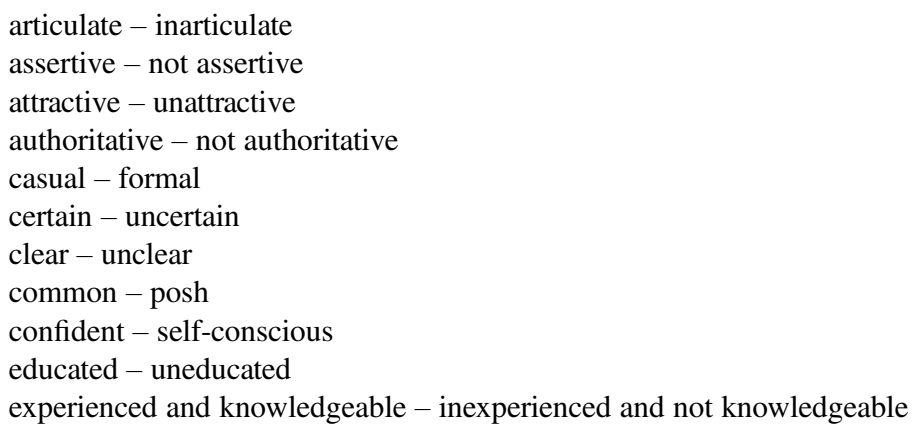




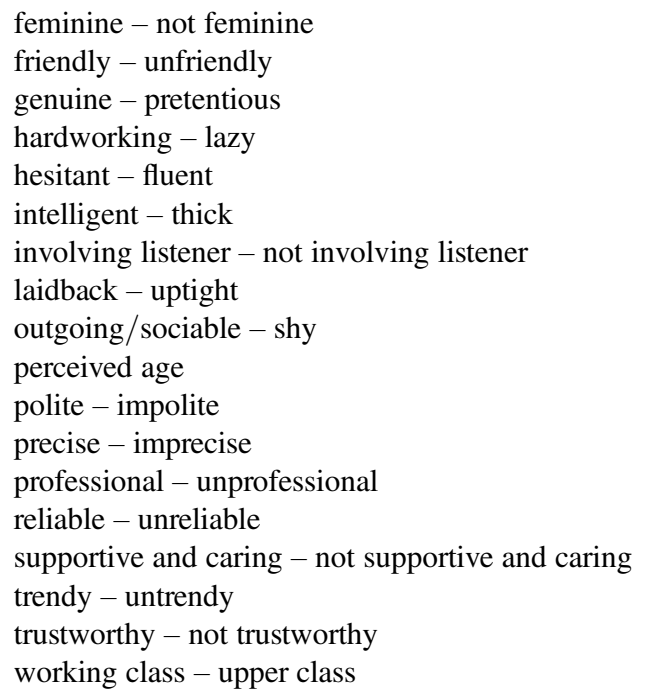

\section{R E F E R E N C E S}

Acton, Eric K., \& Christopher Potts (2014). That straight talk: Sarah Palin and the sociolinguistics of demonstratives. Journal of Sociolinguistics 18:3-31.

Agha, Asif (2005). Voice, footing, enregisterment. Journal of Linguistic Anthropology 15:38-59.

Anderson, Gisle (2000). The role of pragmatic marker like in utterance interpretation. In Gisle Andersen \& Thorstein Fretheim (eds.), Pragmatic markers and propositional attitude, 17-38. Amsterdam: John Benjamins.

Baayen, R. Harald (2008). Analyzing linguistic data: A practical introduction to statistics using $R$. Cambridge: Cambridge University Press.

Beeching, Kate (2016). Pragmatic markers in British English: Meaning in social interaction. Cambridge: Cambridge University Press.

Beltrama, Andrea, \& Emily A. Hanik (2018). Marking imprecision, conveying surprise: Like between hedging and mirativity. Journal of Linguistics 55:1-34.

— \& Laura Staum Casasanto (2017). Totally tall sounds totally younger: Intensifiers at the sociosemantic interface. Journal of Sociolinguistics 21:154-82.

Boersma, Paul, \& David Weenink (2014). Praat: Doing phonetics by computer [computer program]. Version 5.3.82. Online: http://www.praat.org/; accessed January 2015.

Bohner, Gerd, \& Nina Dickel (2011). Attitudes and attitude change. Annual Review of Psychology 62:391-417.

Bortfeld, Heather; Silvia D. Leon; Jonathan E. Bloom; Michael F. Schober; \& Susan E. Brennan (2001). Disfluency rates in conversation: Effects of age, relationship, topic, role, and gender. Language and Speech 44:123-47.

Buchstaller, Isabelle (2014). Quotatives: New trends and sociolinguistic implications. Malden, MA: Wiley-Blackwell.

Campbell-Kibler, Kathryn (2007). Accent, (ING) and the social logic of listener perceptions. American Speech 82:32-64.

(2009). The nature of sociolinguistic perception. Language Variation and Change 21:135-56.

(2011). The sociolinguistic variant as a carrier of social meaning. Language Variation and Change 22:423-41. 


\section{ERIK SCHLEEF}

Costello, Anna B., \& Jason W. Osborne (2005). Best practices in exploratory factor analysis: Four recommendations for getting the most from your analysis. Practical Assessment Research \& Evaluation 10:1-9.

Crystal, David, \& Derek Davy (1975). Advanced conversational English. London: Longman.

D'Arcy, Alexandra (2007). Like and language ideology: Disentangling fact from fiction. American Speech 82:386-419.

Dailey-O'Cain, Jennifer (2000). The sociolinguistic distribution of and attitudes toward focuser like and quotative like. Journal of Sociolinguistics 4:60-80.

Davydova, Julia (2021). The role of sociocognitive salience in the acquisition of structured variation and linguistic diffusion: Evidence from quotative be like. Language in Society 50:171-96.

—; Agnieszka Ewa Tytus; \& Erik Schleef (2017). Acquisition of sociolinguistic awareness by German learners of English: A study in perceptions of quotative be like. Linguistics 55:783-812.

Drager, Katie K. (2011). Sociophonetic variation and the lemma. Journal of Phonetics 39:694-707.

Duez, Danielle (1993). Acoustic correlates of subjective pauses. Journal of Psycholinguistic Research 22:21-39.

Eckert, Penelope (2008). Variation and the indexical field. Journal of Sociolinguistics 12:453-76.

Fazio, Russell (1986). How do attitudes guide behaviour? In Richard Sorrentino \& Edward Higgins (eds.), Handbook of motivation and cognition: Foundations of social behaviour, 204-43. New York: Guildford Publications.

(2007). Attitudes as object-evaluation association of varying strength. Social Cognition 25:115-41.

Fought, Carmen (2006). Interviewed on the Today Show, May 9. Cited in 'Like it or not, a discourse marker making its mark on a wider stage', Voice of America News, May 6, 2006. Transcript and audio files available at http://www.voanews.com/specialenglish/archive/2006-05/2006-05-09voa5.cfm.

Goldman-Eisler, Frieda (1968). Psycholinguistics: Experiments in spontaneous speech. London: Academic Press.

Greenwald, Anthony G. (1976). Within-subjects designs: To use or not to use? Psychological Bulletin 83:314-20.

Hay, Jennifer; Katie Drager; \& Paul Warren (2010). Short-term exposure to one dialect affects processing of another. Language and Speech 53:447-71.

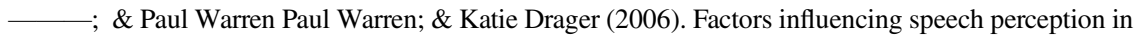
the context of a merger-in-progress. Journal of Phonetics 34:458-84.

Hesson, Ashley, \& Madeline Shellgren (2015). Discourse marker like in real time: Characterizing the time-course of sociolinguistic impression making. American Speech 90:154-86.

Holmes, Janet (1986). Functions of you know in women's and men's speech. Language in Society 15:1-22.

Johnstone, Barbara; Jennifer Andrus; \& Andrew E. Danielson (2006). Mobility, indexicality, and the enregisterment of 'Pittsburghese'. Journal of English Linguistics 34:77-104.

Kahng, Jimin (2018). The effect of pause location on perceived fluency. Applied Psycholinguistics 39:569-91.

Kendall, Tyler (2013). Speech rate, pause, and sociolinguistic variation. Basingstoke: Palgrave Macmillan.

Levey, Stephen (2003). He's like 'Do it now!' and I'm like 'No!': Some innovative quotative usage among young people in London. English Today 19:24-32.

Levon, Erez (2007). Sexuality in context: Variation and the sociolinguistic perception of identity. Language in Society 36:533-44.

(2014). Categories, stereotypes and the linguistic perception of sexuality. Language in Society 43:539-66.

\& Sue Fox (2014). Social salience and the sociolinguistic monitor: A case study of (ING) and TH-fronting in Britain. Journal of English Linguistics 42:185-217. 
Maclay, Howard, \& Charles E. Osgood (1959). Hesitation phenomena in spontaneous English Speech. Word 15:19-44.

Maddeaux, Ruth, \& Aaron Dinkin (2017). Is like like like?: Evaluating the same variant across multiple variables. Linguistics Vanguard 3. Online: https://doi.org/10.1515/lingvan-2015-0032.

Pharao, Nicolai, \& Marie Maegaard (2017). On the influence of coronal sibilants and stops on the perception of social meanings in Copenhagen Danish. Linguistics 55:1141-67.

R Core Team (2019). R: A language and environment for statistical computing. Online: https://www.Rproject.org/.

Schleef, Erik (2017). Social meanings across listener groups: When do social factors matter? Journal of English Linguistics 45:28-59.

(2019). The evaluation of unfilled pauses: Limits of the prestige, solidarity and dynamism dimensions. Lingua 228:1-16.

_ \& Nicholas E. J. Flynn (2015). Ageing meanings of (ing): Age and indexicality in Manchester, England. English World-Wide 36:48-90.

- Nicholas Flynn; \& Will Barras (2017). Regional diversity in social perceptions of (ing). Language Variation and Change 29:29-56.

- \& Danielle Turton (2018). Sociophonetic variation of like in British dialects: Effects of function, context and predictability. English Language and Linguistics 22:35-75.

Siegel, Muffy (2002). Like: The discourse particle and semantics. Journal of Semantics 19:35-71.

Silverstein, Michael (2003). Indexical order and the dialectics of sociolinguistic life. Language and Communication 23:193-229.

Streiner, David L. (1994). Figuring out factors: The use and misuse of factor analysis. Canadian Journal of Psychiatry 39:135-40.

Survey Gizmo (2015). SurveyGizmo [Survey software website]. Online: https://www.surveygizmo. com; accessed January 2015.

Tannen, Deborah (1985). Silence: Anything but. In Deborah Tannen \& Muriel Saville-Troike (eds.), Perspectives on silence, 93-111. Norwood, NJ: Ablex.

Walker, Anne Graffam (1985). The two faces of silence: The effect of witness hesitancy on lawyers' impressions. In Deborah Tannen \& Muriel Saville-Troike (eds.), Perspectives on silence, 55-75. Norwood, NJ: Ablex.

Warren, Paul (2013). Introducing psycholinguistics. Cambridge: Cambridge University Press.

Zahn, Christopher J., \& Robert Hopper (1985). Measuring language attitudes: The speech evaluation instrument (SEI). Journal of Language and Social Psychology 4:113-23.

Zellner, Brigitte (1994). Pauses and the temporal structure of speech. In Eric Keller (ed.), Fundamentals of speech synthesis and speech recognition, 41-62. Chichester: John Wiley.

(Received 12 April 2020; revision received 12 February 2021; accepted 20 February 2021; final revision received 14 March 2021)

Address for correspondence: Erik Schleef

English and American Studies

University of Salzburg, Austria

Erzabt-Klotz-Straße 1, Unipark Nonntal 5020 Salzburg, Austria Erik.schleef@sbg.ac.at 